\title{
Revealing the nucleation kinetics of primary Si particles in hypereutectic Al-Si alloys under the influence of $\mathbf{P}$ inoculation
}

\author{
Yijiang $\mathrm{Xu}^{1}$, Yun Deng ${ }^{2}$, Daniele Casari ${ }^{3}$, Ragnvald H. Mathiesen ${ }^{3}$, Xiangfa Liu ${ }^{4}$, and \\ Yanjun $\mathrm{Li}^{1, *}$ (D) \\ ${ }^{1}$ Department of Materials Science and Engineering, Norwegian University of Science and Technology (NTNU), 7491 Trondheim, \\ Norway \\ ${ }^{2}$ Department of Mechanical and Industrial Engineering, Norwegian University of Science and Technology (NTNU), 7491 Trondheim, \\ Norway \\ ${ }^{3}$ Department of Physics, Norwegian University of Science and Technology (NTNU), 7491 Trondheim, Norway \\ ${ }^{4}$ Key Laboratory for Liquid-Solid Structural Evolution and Processing of Materials (Ministry of Education), Shandong University, No. \\ 17923 Jingshi Road, Jinan 250061, China
}

Received: 27 February 2020

Accepted: 5 July 2020

Published online:

14 August 2020

(C) The Author(s) 2020

\begin{abstract}
A quantitative study on the kinetics of nucleation of primary Si particles (PSPs), especially under the effect of $\mathrm{P}$ inoculation, during isothermal melt solidification of hypereutectic $\mathrm{Al}-\mathrm{Si}(-\mathrm{Cu})$ alloys has been realized for the first time by using a unique micro-focus in situ X-radiography method, which is impossible by synchrotron X-radiography or tomography methods. The nucleation undercooling and nucleation rate of PSPs have been measured. Besides, TP-1 type solidification test has been carried out. It is found that nucleation undercooling of PSPs is reduced, while nucleation rate and number density of PSPs is increased significantly by $\mathrm{P}$ inoculation. Moreover, the influence of cooling rate on the nucleation kinetics of PSPs in the P inoculated alloy was investigated in situ. It is observed that higher cooling rate has the influence of increasing the peak nucleation rate and extending the nucleation temperature ranges of PSPs, in terms of earlier nucleation at lower undercooling and nucleation stopping at higher undercooling, which results in higher number density of PSPs. The decrease in minimum nucleation undercooling with increasing cooling rate in the P inoculated alloy is unexpected, which has been attributed to the extremely slow growth rate of faceted Si crystal on AlP substrates under low undercooling.
\end{abstract}

Address correspondence to E-mail: yanjun.li@ntnu.no 


\section{Introduction}

Hypereutectic Al-Si alloys are widely used to produce engine parts due to their low density, hightemperature resistance, high wear resistance, and low coefficient of thermal expansion [1-4]. The mechanical and physical properties of these alloys are strongly influenced by the size and morphology of the primary silicon particles (PSPs), which can have different morphologies, including octahedral, polyhedral, feathery-like, star-like containing two to five branches, and hexagonal-shaped plates $[1,3,5,6]$. Fine primary Si particles with compact morphology (e.g. polyhedral) are beneficial for the strength, ductility and wear resistance of alloys, while coarse starlike, lath/plate-like or dendritic morphologies with long branches are harmful. The size and morphology are mainly controlled by the nucleation and growth of the particles during solidification, which are influenced by the inoculation or modification treatment and solidification conditions $[1,7,8]$.

For hypereutectic Al-Si alloys without modification/inoculation, the morphologies of PSPs are strongly influenced by cooling rate and silicon contents in the alloys. The size of primary silicon decreases with increasing cooling rate $[3,7,9,10]$ and decreasing Si contents. However, the shape change from the common plate and star-like shapes to octahedral shapes only occurs when the cooling rate is higher than certain critical values while the Si content is low enough. Ullah et al. [11] investigated the influence of silicon content (17-38 wt.\%) on the morphologies of silicon crystals formed during solidification of Al-Si alloys, and showed that the $\mathrm{Si}$ particles have a fish-bone or star-like morphology at lower silicon contents, but change to large plates at higher $\mathrm{Si}$ contents. Some studies have revealed that molten hypereutectic Al-Si alloys have a non-homogeneous spatial distribution of $\mathrm{Si}$ atoms with a shortrange atomic order (cluster) at temperatures above liquidus [12-14]. It is suggested that these clusters act as nucleation sites and facilitate primary $\mathrm{Si}$ formation [7, 12-14]. The size of Si-Si clusters would directly influence the formation of nucleus of different $\mathrm{Si}$ morphologies. The number density of $\mathrm{Si}-\mathrm{Si}$ clusters determines the size of PSPs after casting. This was supposed to be the reason that an over-heating of the aluminium melt before casting can significantly change the morphology of primary Si particles, from star-like and other irregular shapes to octahedral shapes $[3,7,9-12]$, and at the same time reduce the size of Si particles $[7,10]$.

Phosphorus (P) in the form of Al-P, Al-Si-P or Cu$\mathrm{P}$ master alloy, is usually introduced into the hypereutectic Al-Si alloys to refine primary silicon particles [1], which was first suggested by Sterner-Rainer [15]. In addition to the refinement effect, addition of $\mathrm{P}$ can also change the morphology of PSPs from irregular to polyhedral [3]. For the corresponding refinement mechanism, it is generally accepted that AlP particles act as the nucleation substrate for the heterogeneous nucleation of PSPs, where a cube-cube orientation relationship exists between AlP and PSPs [1, 3, 16].

In the last decades, the mechanism and kinetics of heterogeneous nucleation of non-faceted phase, for example aluminium grains in aluminium alloys, has been extensively studied both experimentally and by modelling [17-26], where the application of synchrotron X-radiography and micro-focus X-radiography methods has greatly facilitated the acquisition of quantitative kinetic data. In contrast, little research efforts have been spent to quantitatively address the nucleation kinetics of faceted crystals, for example primary $\mathrm{Si}$ phase, especially under the influence of $\mathrm{P}$ addition, in hypereutectic aluminium-silicon alloys. This should be attributed to the limit of synchrotron $X$-ray radiography or tomography facilities, where the thin samples have to be aligned in a vertical configuration. Within the vertically positioned thin sample (broad plane parallel to gravity), there is a strong floating of the PSPs due to the big density difference between them and surrounding liquid metal.

So far experimental studies on nucleation behaviour of PSPs have been mostly limited to ex situ, e.g. thermal analysis during solidification, characterization of the size and morphology of primary $\mathrm{Si}$, and finding the potential nucleation site [27-31]. However, it is difficult to reveal the nucleation kinetics quantitatively by ex situ characterization, where detailed temporal information is missing. Fortunately, the development of in situ micro-focus X-radiography method has made the quantitative study possible, because thin plate samples can be positioned with their broad faces perpendicular to the gravity.

In this work, for the first time, in situ micro-focus $\mathrm{X}$-radiography has been applied to study the nucleation kinetics of primary $\mathrm{Si}$ particles during 
solidification of high-purity hypereutectic Al-Si alloys without and with P addition. Near-isothermal melt solidification condition with constant cooling rates has been used. Besides, TP-1 type solidification test has been carried out.

\section{Materials and experimental methodologies}

The base material used in this work is an Al22wt.\%Si-18.8wt.\%Cu alloy prepared from $5 \mathrm{~N}$ (99.999\%) high-purity aluminium, solar-grade $6 \mathrm{~N}$ (99.9999\%) high-purity Si and 6 N (99.9999\%) highpurity $\mathrm{Cu}$, molten in a clay graphite crucible using a Nabertherm melting furnace. The aim of adding $\mathrm{Cu}$ into the alloy is to enhance the X-radiography contrast between primary Si phase and the liquid phase, which has been demonstrated previously by Mathiesen et al. [32] and Shahani et al. [33, 34] in Al$\mathrm{Si}-\mathrm{Cu}$ system. The phase diagram and phase mole fraction evolution as a function of temperature calculated by Thermo-Calc [35] using the TCAL4 database are shown in Fig. 1. The theoretical liquidus temperature is calculated as $770.2{ }^{\circ} \mathrm{C}$ (\#1 marked in Fig. 1) with $\mathrm{Si}$ as the primary phase to form during solidification. In comparison to the binary $\mathrm{Al}-\mathrm{Si}$ phase diagram (dash lines), the addition of $\mathrm{Cu}$ mainly changes the liquidus temperature, but has very modest influence on the slope of the liquidus line. The solubility of $\mathrm{Cu}$ in solid $\mathrm{Si}$ is less than $0.5 \mathrm{ppm}[36,37]$, thus the added $\mathrm{Cu}$ remains almost completely in the liquid. Previous investigation [34] has also shown that the dissolved $\mathrm{Cu}$ does not modify the diffusion mobility of $\mathrm{Si}$ in the aluminium melt noticeably. In addition, $\mathrm{Cu}$ does not alter the potency of AlP particles [32, 38]. Therefore, it is considered that $\mathrm{Cu}$ does not affect the nature of nucleation and growth behaviour of PSPs. Moreover, adding $\mathrm{Cu}$ also reduces the binary $\mathrm{Al}-\mathrm{Si}$ eutectic temperature (\#2 shown in Fig. 1) and results in a ternary eutectic reaction (indicated by \#3 with vertical lines in Fig. 1) at $521.6{ }^{\circ} \mathrm{C}$. As shown in Fig. 1b, in this ternary eutectic stage, all of the residual liquid transforms to solid, meanwhile about $40 \% \mathrm{Al}$ phase, $4 \% \mathrm{Si}$ phase and $25 \% \mathrm{Al}_{2} \mathrm{Cu}$ phase form. The final molar fraction of different phases is shown by a single point for each phase. After complete melting and mixing of the raw materials at $800{ }^{\circ} \mathrm{C}, 0.5 \mathrm{wt} . \% \mathrm{Al}-3 \mathrm{P}$ master alloy was added. The microstructure of AlP particles in the master alloy has been characterized and reported in $[39,40]$. The phosphorus contents in the base alloy without $\mathrm{P}$ addition and in the alloy with $\mathrm{P}$ addition are measured by Glow Discharge Mass Spectrometry (GDMS) as $0.47 \mathrm{ppm}$ and $110 \mathrm{ppm}$, respectively. In the later sections, these two alloys are named as non-inoculated and P inoculated $\mathrm{Al}-\mathrm{Si}-\mathrm{Cu}$ alloys.

For TP-1 type test, the two experimental alloys were solidified in a small pre-heated (the same temperature as the melt, $\sim 800{ }^{\circ} \mathrm{C}$ ) graphite crucible $(\Phi=48 \mathrm{~mm}, \mathrm{H}=50 \mathrm{~mm})$ covered with insulation materials at the bottom and top. A well-calibrated

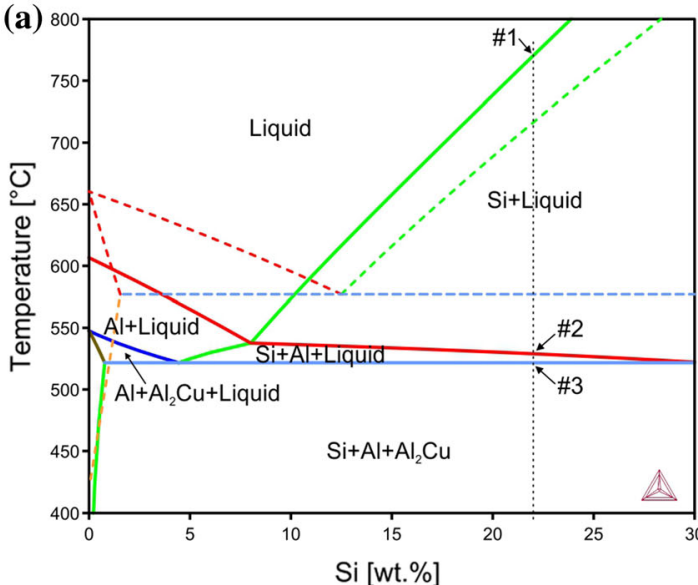

Figure 1 a Phase diagram of $\mathrm{Al}-18.8 \mathrm{Cu}-\mathrm{xSi}$ and $\mathrm{Al}-\mathrm{Si}$ alloy and b phase mole fraction evolution as a function of temperature of Al-22Si-18.8Cu alloy based on Scheil model calculated by Thermo-Calc. \#1 represents the liquidus temperature $\left(770.2{ }^{\circ} \mathrm{C}\right)$

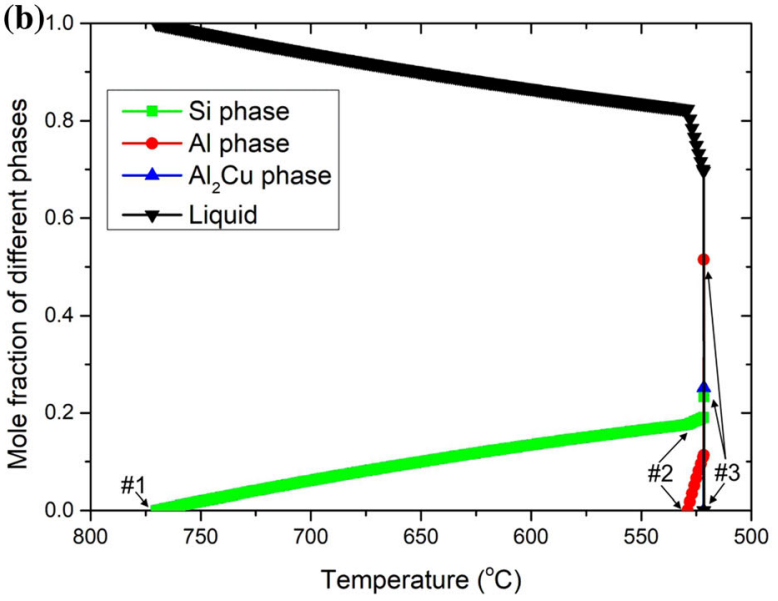

below which primary Si forms, \#2 represents Al-Si binary eutectic temperature $\left(528.9^{\circ} \mathrm{C}\right.$ ) and $\# 3$ represents $\mathrm{Al}-\mathrm{Si}-\mathrm{Al}_{2} \mathrm{Cu}$ ternary eutectic point $\left(521.6^{\circ} \mathrm{C}\right)$. 
K-type thermocouple was inserted into the centre of the crucible to measure the cooling curves during solidification at $50 \mathrm{~Hz}$ recording rate. After solidification experiments, the small cast ingots $(\Phi=30 \mathrm{~mm}$, $H=40 \mathrm{~mm}$ ) were sectioned, ground and polished for microstructure characterization using ZEISS Axiovert 25 optical microscope.

For the in situ solidification experiments, plate-like thin samples were first cut from the as-cast ingots and then ground and polished into final dimensions of $5 \mathrm{~mm} \times 50 \mathrm{~mm} \times 0.2 \mathrm{~mm} \quad(X \times Y \times Z) \pm 0.01$ $\mathrm{mm}$. The thin sample together with a steel sample holder were then encapsulated into glassy carbon crucibles. The micro-focus $X$-ray radiography setup used here for in situ solidification studies has been widely used for $\mathrm{Al}$ alloys [17, 18, 41-43] and $\mathrm{Mg}$ alloys [44] and the detailed description of the whole setup could be found in Refs. [42, 45, 46]. The thin plate samples are melted and solidified inside the Bridgman-type gradient furnace in a horizontal position, namely, the wide surface of the sample is perpendicular to the gravity direction $(\mathrm{Z} / \mathrm{g})$. By this sample configuration, melt convection could be suppressed to a large extant and the crystal/particle movement due to gravity/flotation is limited mainly in the sample thickness direction ( $Z$ direction), which simplify the condition for studying the nucleation kinetics of primary silicon. Nearly isothermal melt solidification condition was realized by fine-tuning the two heater elements of the furnace [17, 41]. For each in situ solidification sequence, the sample was remelted and heated to a temperature $\sim 790{ }^{\circ} \mathrm{C}$. Each sample was subjected to several repeated sequences over the same FOV, and experiments were carried out on more than one samples with identical furnace settings. Constant cooling rates in the range of $0.05-1 \mathrm{~K} / \mathrm{s}$ were applied for the solidification experiments. During in situ solidification experiments, temperature curves at two heater elements outside of the field-of-view (FOV) are recorded. The melt temperature inside the FOV is calculated from the average values of the temperatures of two heater elements but further calibrated with the binary Al-Si eutectic temperature of this ternary alloy, as shown by point \#2 in the phase diagram plotted in Fig. 1. The field-of-view (FOV) of X-radiographic images is about $2700 \times 1800 \mu \mathrm{m}^{2}$ and the frame capture rate was set to $1 \mathrm{~Hz}$.

\section{Results}

\section{TP-1 type solidification study}

The solidification structure of TP- 1 type samples is shown in Fig. 2, where the primary Si particles show a black contrast. The non-inoculated base alloy shows coarse irregularly shaped PSPs, with different morphologies including star-like, five-fold branched shape, plate-like shape and hollow octahedron shape. The average size of PSP was measured as $396 \mu \mathrm{m}$. In contrast, the PSPs in the P inoculated sample are much finer and mostly have more blocky shapes with an average size of about $88.6 \mu \mathrm{m}$, showing the significant refinement effect of Al-3P master alloy on primary Si particles. In addition to PSPs, a large fraction of fine $\mathrm{Al}-\mathrm{Si}-\mathrm{Al}_{2} \mathrm{Cu}$ ternary eutectic structure (light grey region) and a small fraction of $\mathrm{Al}$ dendrite phase (bright) can be observed.

Figure 3 shows the measured cooling curves of TP1 type samples during solidification in the graphite crucible. The corresponding first derivatives of cooling curves, $\mathrm{d} T / \mathrm{d} t$, are also shown in the figure. The initial cooling rate during solidification is measured as $\sim 1.6 \mathrm{~K} / \mathrm{s}$. Following the typical data analysis methods of cooling curves [47, 48], the nucleation starting temperature $T_{n}$ of the primary phase (here primary $\mathrm{Si}$ ) is defined as the temperature at which the cooling curve start to deviate from linearity, or the first peak showing in $\mathrm{d} T / \mathrm{d} t$ curve. The starting temperature of nucleation in the $\mathrm{P}$ inoculated alloy is determined as $735.4{ }^{\circ} \mathrm{C}$, which is $31.8^{\circ} \mathrm{C}$ higher than that for the base alloy without $\mathrm{P}$ addition $\left(703.6^{\circ} \mathrm{C}\right)$, showing that the nucleation undercooling is greatly reduced by addition of the Al-3P master alloy. In the late solidification stage, at around $T=525^{\circ} \mathrm{C}$ $(t=293 \mathrm{~s})$, a second peak of $\mathrm{dT} / \mathrm{d} t$ followed by recalescence stage can be observed for both alloys. Based on the calculated phase diagram shown in Fig. 1, this is corresponding to the binary eutectic reaction $\mathrm{L} \rightarrow \mathrm{Al}+\mathrm{Si}$ at $528.9^{\circ} \mathrm{C}$ (\#2 in Fig. 1), where about $11 \mathrm{vol} . \% \mathrm{Al}$ phase and $1 \mathrm{vol} . \%$ Si phase form in this stage. It is consistent with the dendritic $\mathrm{Al}$ phase shown in Fig. 2. The recalescence phenomenon should be ascribed to the formation of the divorced eutectic Al phase which releases a large amount of latent heat. It is interesting to see that the two peaks of $\mathrm{d} T / \mathrm{d} t$ corresponding to the binary eutectic reaction are nearly overlapping, showing that the nucleation temperature of $\mathrm{Al}-\mathrm{Si}$ eutectic in the two alloys 

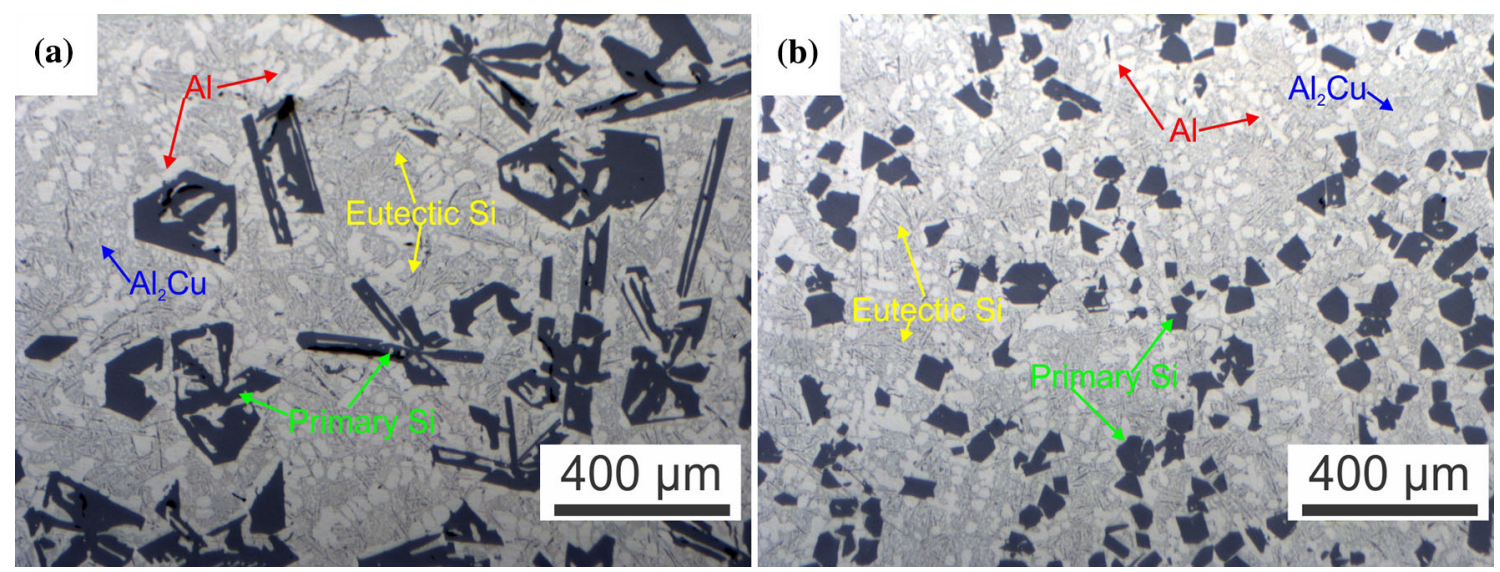

Figure 2 Microstructure of primary Si particles in the TP-1 type solidification samples characterized by optical microscope: a noninoculated and b 110 ppm P inoculated $\mathrm{Al}-22 \mathrm{Si}-18.8 \mathrm{Cu}$ alloys. Different phases are marked in the images.

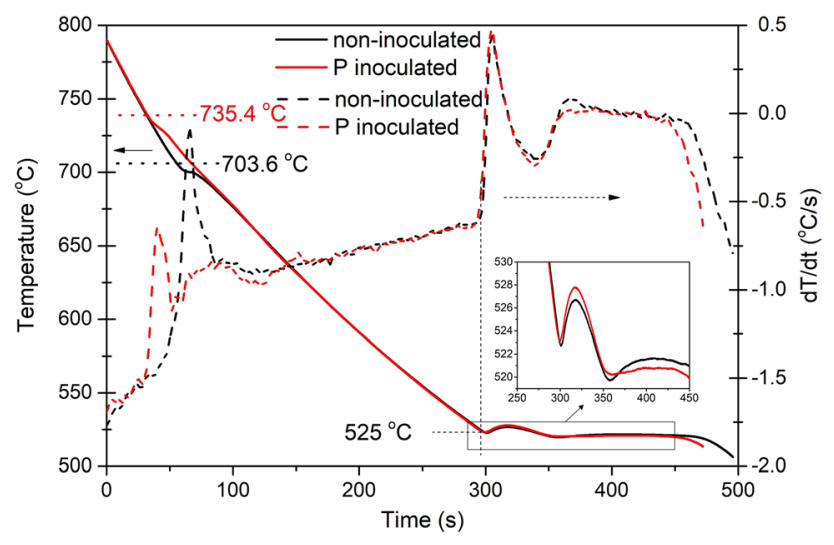

Figure 3 Cooling curves (solid lines) of non-inoculated and $110 \mathrm{ppm} \mathrm{P}$ inoculated $\mathrm{Al}-22 \mathrm{Si}-18.8 \mathrm{Cu}$ alloys measured during TP-1 type solidification in the graphite crucible and the corresponding first derivative $\mathrm{dT} / \mathrm{dt}$ curves (dashed lines).

are nearly the same, while the cooling curve measurement is reproducible. The third peak of $\mathrm{dT} /$ $\mathrm{d} t$ and the following plateaus in the cooling curves are corresponding to the ternary eutectic reaction in the alloys. The temperature at plateaus for the noninoculated and $\mathrm{P}$ inoculated alloy is $521.6{ }^{\circ} \mathrm{C}$ and $520.8^{\circ} \mathrm{C}$, respectively, which is in a good agreement with the theoretical ternary eutectic temperature, $521.6{ }^{\circ} \mathrm{C}$ (\#3 in Fig. 1). The cooling curves show that the addition of $\mathrm{P}$ also reduces the nucleation undercooling of the ternary eutectic reaction.

\section{In situ X-radiographic study on the nucleation behaviour of PSPs \\ Solidification at cooling rate of $0.2 \mathrm{~K} / \mathrm{s}$}

Selected images from in situ X-radiography sequences recorded during near-isothermal melt solidification of non-inoculated and $\mathrm{P}$ inoculated hypereutectic Al-22Si-18.8Cu alloys under $0.2 \mathrm{~K} / \mathrm{s}$ cooling rate are shown in Fig. 4 . The full video sequences are also provided in Video 1 and Video 2 as supplementary materials. The images in the left column are for the non-inoculated and the right for the $\mathrm{P}$ inoculated alloy, respectively. In each solidification case, when the first Si particle becomes visible in the FOV, the time is set to $t=0 \mathrm{~s}$. The melt temperature is obtained from temperatures recorded by thermocouples calibrated with the temperature of $\mathrm{Al}$ dendrites forming in the $\mathrm{FOV}$ (assuming $\mathrm{Al}$ grain forms at the theoretical temperature of $T=528.9^{\circ} \mathrm{C}$ ). The detailed formation of $\mathrm{Al}$ grains form after PSPs and the microstructure in post solidified samples have already been reported in [46]. Due to the difference of $\mathrm{Cu}$ concentration between the liquid and solid phases, the primary Si crystals forming in the liquid (some are indicated by red arrows) show a bright contrast while the liquid remains dark. As can be seen, PSPs appear nearly homogeneously in the whole FOV, indicating that there is no significant temperature gradient in the FOV and a nearisothermal melt solidification is achieved. It is observed that the PSPs started to form at $762.1^{\circ} \mathrm{C}$ in the P inoculated alloy (Fig. 4b1). In contrast, no PSPs could be observed until $755.3{ }^{\circ} \mathrm{C}$ in the non- 


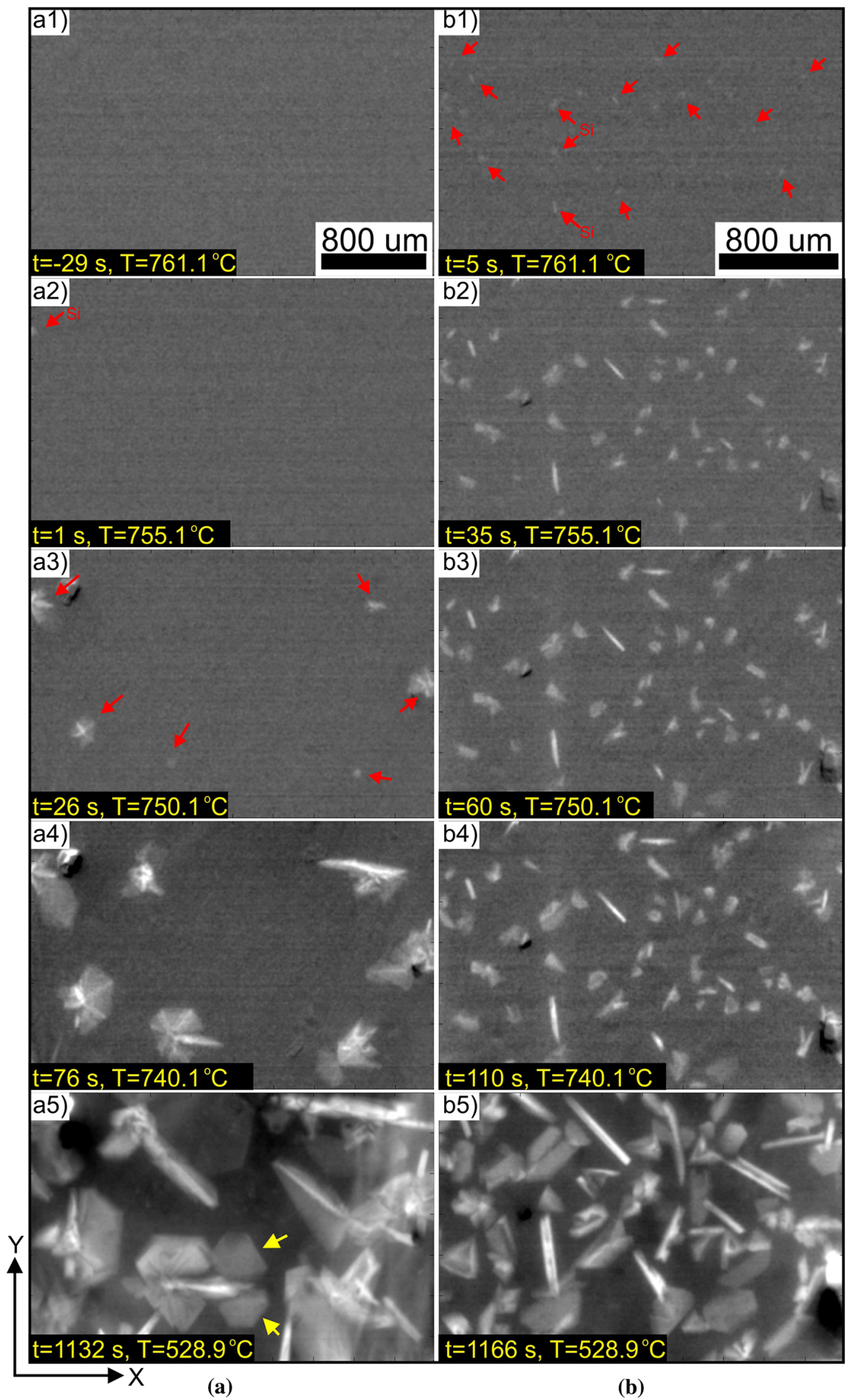


4 Figure 4 Selected X-radiographic images from in situ studies of solidification of a non-inoculated and $\mathbf{b} 110 \mathrm{ppm} \mathrm{P}$ inoculated Al$22 \mathrm{Si}-18.8 \mathrm{Cu}$ alloys under the same cooling rate of $0.2 \mathrm{~K} / \mathrm{s}$. Primary Si particles show a bright contrast, and some of them are marked with red arrows. The full video sequences are also provided in Video 1 and Video 2.

inoculated alloy (Fig. 4a2). It shows that the P addition significantly reduces the nucleation undercooling for PSPs.

After nucleation, a faceted growth of PSPs can be seen in both alloys. In the base alloy without $P$ addition, most of the PSPs show complex star-like morphologies with branches and fan-like thin plates extending into the surrounding $\mathrm{Al}$ liquid in the early stage of formation. With temperature decreasing, the plates and branches grow into larger size. Formation of new plates (marked by yellow arrows in Fig. 4a5) from the growing Si crystals can also be observed. In contrast to the non-inoculated alloy, most of the $\mathrm{Si}$ particles have polyhedron and plate-like morphologies in the $\mathrm{P}$ inoculated alloy. Formation of new branches or new plates from the growing crystals are rare. Besides, the size of PSPs in the P inoculated alloy is much finer, while the number density is much higher than that in the non-inoculated alloy.

Figure 5 shows the evolution of the total number of primary Si particles formed in the FOV as a function of melt temperature, and the corresponding nucleation rate for the two solidification cases shown in Fig. 4. It can be seen that the nucleation temperature of the primary $\mathrm{Si}$ in the $\mathrm{P}$ inoculated alloy is $6.8 \mathrm{~K}$ higher than that in the non-inoculated alloy. In the non-inoculated alloy, the number of PSPs in the FOV increases slowly with decreasing melt temperature, and reaches a maximum value of 7 after $7.6 \mathrm{~K}$. The maximum nucleation rate is only $2.6 \mathrm{~mm}^{-3} \mathrm{~K}^{-1}$. In the $\mathrm{P}$ added alloy, most of the PSPs in the FOV form in the initial $5.8 \mathrm{~K}$ temperature range after precipitation of the first PSP. The corresponding nucleation rate reaches a peak value $\left(25.9 \mathrm{~mm}^{-3} \mathrm{~K}^{-1}\right)$ within $9 \mathrm{~s}$ (1.8 K undercooling below $T_{n}$ ), followed by a sharp drop, and then remains at low rate for a long time until nucleation stops at $700.5^{\circ} \mathrm{C}$. These results show that the nucleation rate and the final number of PSPs is increased significantly by $\mathrm{P}$ addition.


Figure 5 a Evolution of the total number of primary Si particles (PSPs) in the FOV as a function of melt temperature and $\mathbf{b}$ the corresponding nucleation rate as a function of undercooling during solidification of the two alloys shown in Fig. 4.

\section{Influence of cooling rate on nucleation kinetics of PSPS in $P$ inoculated alloy}

Figure 6 shows selected X-radiographic images from sequences recorded during in situ solidification of the $\mathrm{P}$ inoculated alloy under three different cooling rates, $0.05,0.2$ and $1 \mathrm{~K} / \mathrm{s}$. The undercoolings $\Delta T$ are marked in each image. As can be seen, the total number of PSPs in the FOV increases, while the final size decreases with increasing cooling rate, showing that high cooling rate promotes the nucleation and refinement of PSPs in the P inoculated alloy.

Figure 7a shows the evolution of total number of PSPs in the FOV as a function of undercooling. As can be seen, all the curves show a sigmoid shape. The total number of PSPs increases while the minimum nucleation undercooling required for precipitation of 
(a)

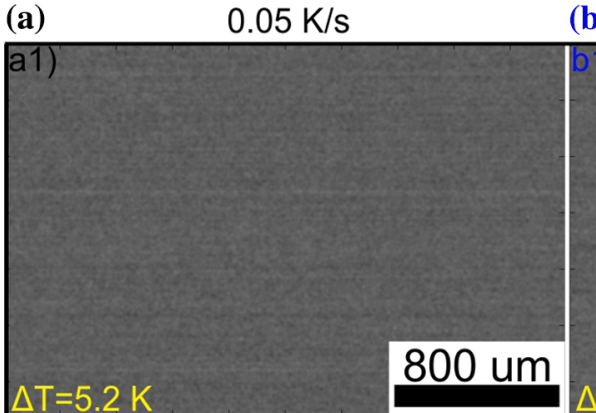

(b)

(b1)



$0.2 \mathrm{~K} / \mathrm{s}$

c)



Figure 6 In situ image sequences of $110 \mathrm{ppm} \mathrm{P}$ inoculated $\mathrm{Al}-22 \mathrm{Si}-18.8 \mathrm{Cu}$ alloy solidified at 3 different cooling rates: a $0.05 \mathrm{~K} / \mathrm{s}$, b $0.2 \mathrm{~K} / \mathrm{s}$ and c $1 \mathrm{~K} / \mathrm{s} . \Delta T$ is the undercooling below liquidus temperature of the alloy.

PSPs decreases as the cooling rate is increased. It is interesting to note that the nucleation of new PSPs can last for a large temperature range, while the maximum nucleation undercooling increases with cooling rate. However, most of the Si particles form in the first $10 \mathrm{~K}$ after nucelation starts. After $15-20 \mathrm{~K}$ undercooling, the increase in rate of PSPs number is very slow. 

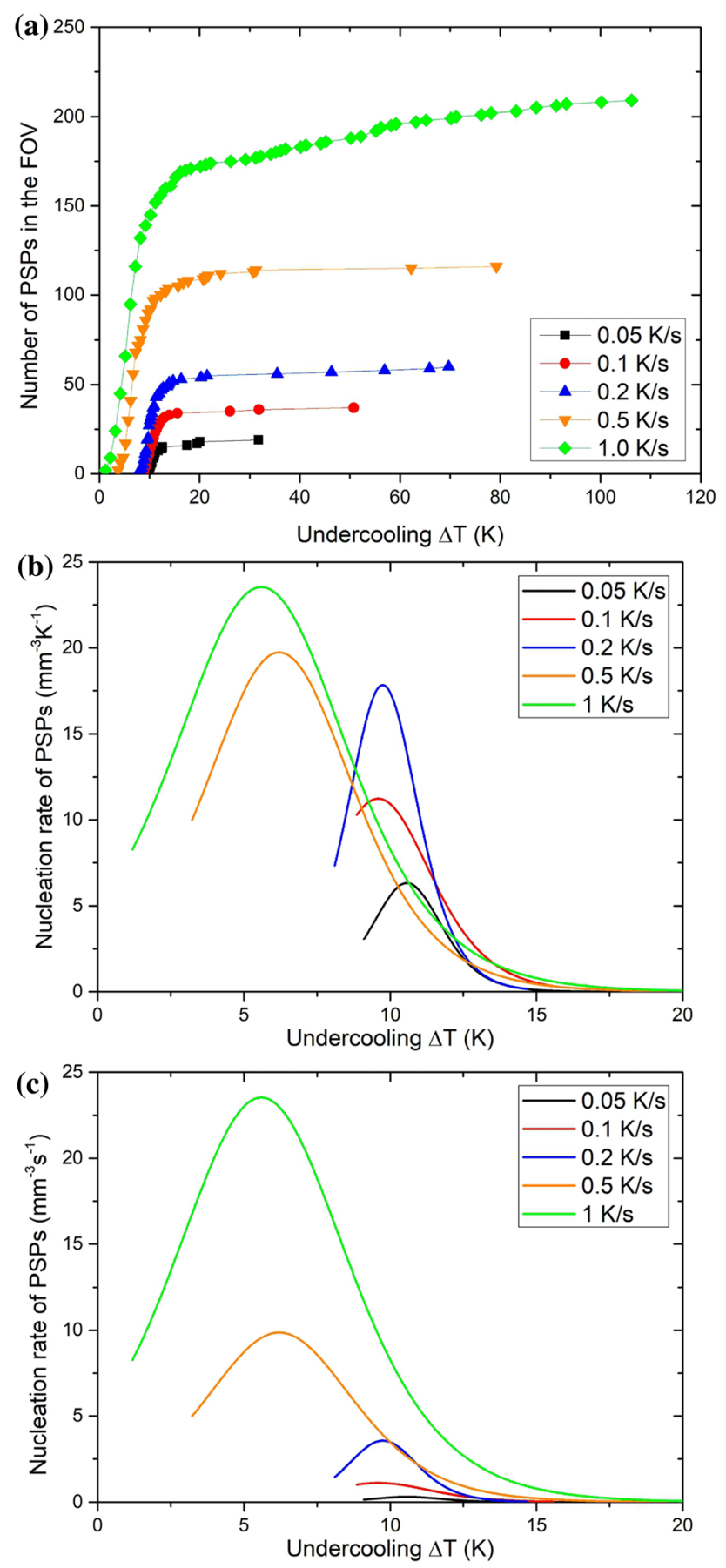

Figure 7 Evolution of number of the PSPs within the FOV as a function of undercooling in the 110 ppm P inoculated Al-22Si$18.8 \mathrm{Cu}$ alloy (the same sample and the same FOV) solidified at different cooling rates (a), the corresponding nucleation rate of PSPs, number density per Kelvin (b) and number density per second (c), calculated from the fitting curves of $\mathbf{a}$.

By fitting the particle number curves in Fig. 7a, in the range of $0-20 \mathrm{~K}$ undercooling, with sigmoid functions, the nucleation rate in units of $\mathrm{mm}^{-3} \mathrm{~K}^{-1}$ and $\mathrm{mm}^{-3} \mathrm{~s}^{-1}$, has been calculated. The corresponding curves are shown in Fig. $7 \mathrm{~b}$ and c, respectively. As can be seen that the nucleation rate curves show a log-normal shape, but with a long tail beyond $15 \mathrm{~K}$ undercooling, where the nucleation rates are extremely low. The peak nucleation rate at higher cooling rates is larger than that for the lower cooling rates. Besides, for the nucleation rate in unit of $\mathrm{mm}^{-3} \mathrm{~s}^{-1}$ (Fig. 7c), at the same undercooling values below $15 \mathrm{~K}$, it almost always increases with cooling rate.

\section{Comparing to non-inoculated alloy}

Figure 8 shows the final volumetric number density of primary Si particles in the non-inoculated and $\mathrm{P}$ inoculated alloys solidified under different cooling rates. As can be seen, the number density of PSPs in both non-inoculated and $\mathrm{P}$ inoculated alloys increases nearly linearly with cooling rate during solidification. However, the increase rate PSPs is much sharper in the latter case ( $\mathrm{P}$ inoculated alloy), indicating a strong effect of $\mathrm{P}$ inoculation on enhancing nucleation.

Figure 9a shows the minimum nucleation undercooling (undercooling below the liquidus temperature when nucleation starts) of the two alloys. For the non-inoculated alloy, the minimum nucleation undercooling generally increases with cooling rate. It is about $17 \mathrm{~K}$ at cooling rates of 0.05 and $0.1 \mathrm{~K} / \mathrm{s}$, while around $20-30 \mathrm{~K}$ at cooling rates 0.5 and $1.0 \mathrm{~K} /$

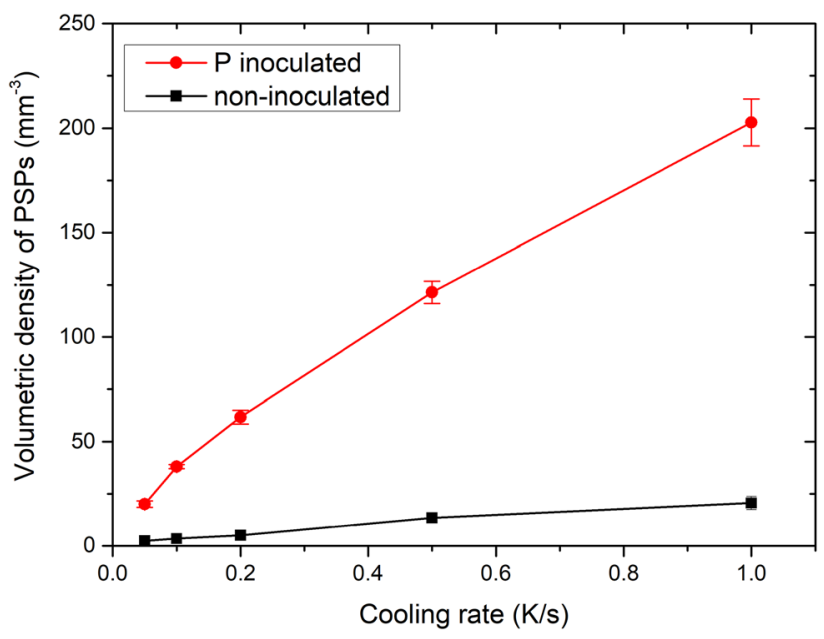

Figure 8 Volumetric number density of primary $\mathrm{Si}$ particles (PSPs) in the non-inoculated and 110 ppm P inoculated Al-22Si$18.8 \mathrm{Cu}$ alloys solidified under different cooling rates. 

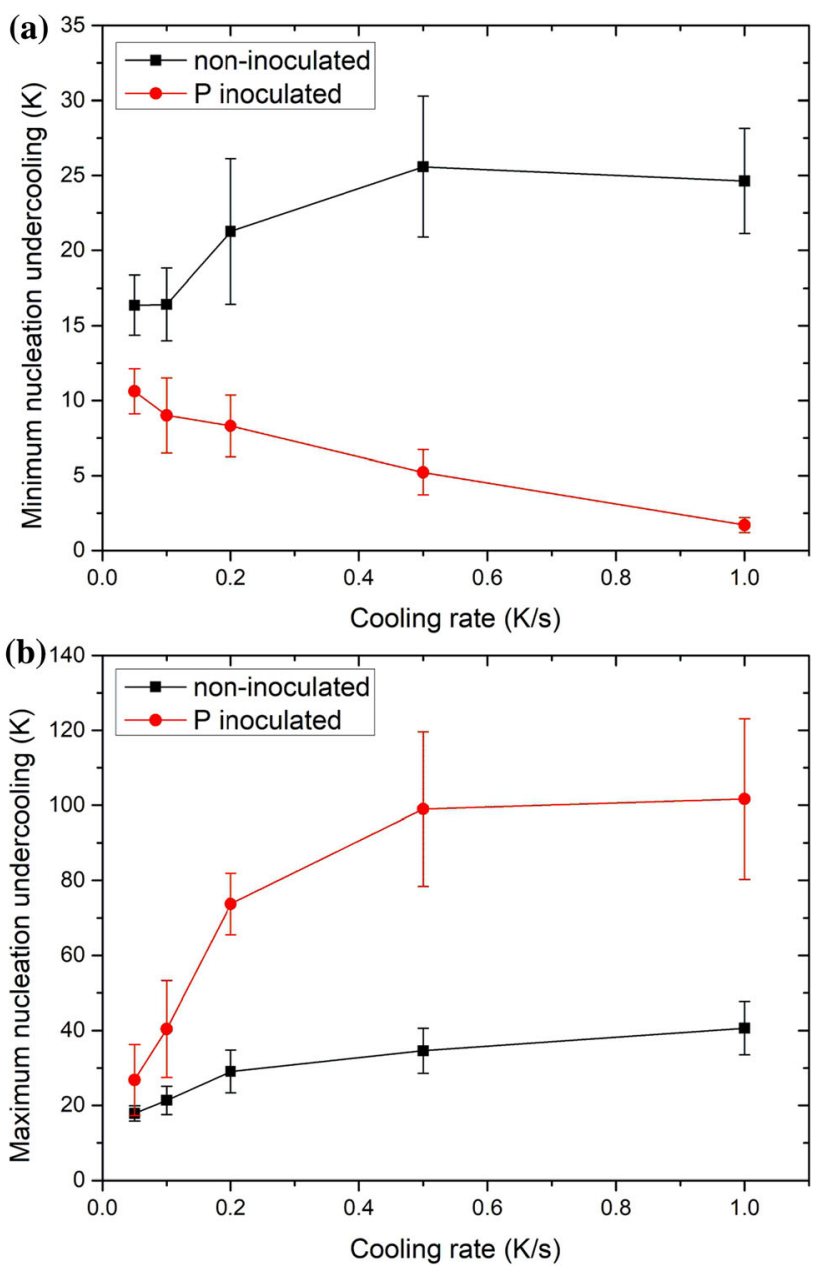

Figure 9 aMinimum Nucleation undercooling and $\mathbf{b}$ maximum nucleation undercooling of primary Si particles measured during in situ solidification of non-inoculated and $110 \mathrm{ppm} P$ inoculated Al-22Si-18.8Cu alloys at different cooling rates. The error bars indicate the standard deviation of the experimental data measured for different solidification experiments.

s. In contrast, the minimum nucleation undercooling of PSPs decreases with cooling rate for the P inoculated alloy, which is an unexpected result. It is about $10.6 \mathrm{~K}$ at cooling rate of $0.05 \mathrm{~K} / \mathrm{s}$, while around $1.7 \mathrm{~K}$ at cooling rate of $1.0 \mathrm{~K} / \mathrm{s}$. This is completely different from the nucleation kinetics of primary aluminium grains in inoculated aluminium alloys where the minimum nucleation undercooling does not change with cooling rate [32]. As shown in Fig. 9b, the maximum nucleation undercooling (undercooling below the liquidus temperature when nucleation stops) increases with cooling rate for both alloys, while much higher values apply for the P inoculated alloy. Such an evolution of maximum nucleation undercooling with cooling rate is consistent with the nucleation kinetics of primary aluminium phase [32]. A larger maximum nucleation undercooling or extended nucleation temperature range is favourable for nucleation of more PSPs. It should be noted that the maximum undercooling determined here is simply determined by the difference between liquidus temperature of the alloy with its nominal composition and the melt temperature, but does not take into account the change of local solute concentration (thus local liquidus temperature) due to the growth of earlier nucleated PSPs.

\section{Discussion}

From the TP-1 type test and in situ X-radiography, it is clear that nucleation of primary $\mathrm{Si}$ particles is greatly enhanced by $\mathrm{P}$ inoculation, in terms of both reduced nucleation undercooling and increased nucleation temperature range. It should be noted that the measured formation temperatures for PSPs by in situ experiments are much higher than that achieved by TP-1 type test. It implies that cooling curve method has a low sensitivity to the starting temperature for precipitation of PSPs, which is different from the high sensitivity to the nucleation of primary $\mathrm{Al}$ grains. This may be attributed to the slow increasing rate for the volume fraction of $\mathrm{Si}$ phase with decreasing temperature, which is about 0.0009 / $\mathrm{K}$ in the present alloy according to equilibrium phase diagram. In comparison, the increasing rate of $\mathrm{Al}$ phase during solidification of Al-20Cu alloy is about $0.0175 / \mathrm{K}$, which is about 19 times higher. Although the latent heat release for precipitation of PSPs per unit volume is about 4 times as that of primary $\mathrm{Al}$ phase, the cooling curve is much less influenced by PSPs. Only when the nucleation and growth rates of PSPs reach certain values, the released latent heat can significantly change the cooling rate of aluminium melt. It should be mentioned that similar small $T_{n}$ was determined in a Al-15Si alloy inoculated by Al-P master alloy by thermal analysis [49].

Based on Al-P phase diagram [50,51] and experimental evidences reported in the literatures $[1,3,16]$, it can be safely concluded that $\mathrm{P}$ provides a large number of AlP particles, acting as nucleation substrates for PSPs. According to the binary Al-P phase diagram calculated from the database developed by Liang and Schmid-Fetzer [50] shown in Fig. 10, 




Figure 10 Al-P phase diagram calculated from the database in Ref. [50] with logarithmic scale for the P composition in wt.\%.

110 ppm $\mathrm{P}$ addition causes AlP particles start to precipitate from the melt at $779.4^{\circ} \mathrm{C}$. Taking into account the effect of solute $\mathrm{Si}$ on P-solubility in the Al-rich melt, AlP particles should be able to precipitate at higher temperatures in Al-Si-P alloy than the binary alloy [51]. Nevertheless, the precipitation temperature of AlP particles is consistently above the liquidus temperature of the alloy, thus AlP particles are available and can work as nucleation sites when PSPs start to precipitate.

In the initial stage of in situ solidification experiments, before cooling starts $\left(790{ }^{\circ} \mathrm{C}\right)$, no AlP particles are supposed to exist in the melt of the $\mathrm{P}$ inoculated alloy. During cooling, AlP particles precipitate and grow when the melt temperature drops below $779.4{ }^{\circ} \mathrm{C}$. When the melt is cooled down below the liquidus temperature of the hypereutectic Al-Si alloy, nucleation of primary Si crystals will be possible, depending on the availability and potency of AlP particles. It has been revealed that low lattice mismatching interfaces exist between the Si crystals and AlP crystals [52, 53], which makes AlP particles highly potent heterogeneous nucleation substrate for PSPs. One can imagine that the size of AlP particles will increase while the number density will decrease with decreasing temperature due to the growth and coarsening of particles. A higher cooling rate will result in a larger number but smaller size of AlP particles in the melt due to the reduced coarsening. On the contrary, a lower cooling rate will result in smaller number of potent AlP particles in the melt. This can well explain the number density increase of PSPs with increasing cooling rate. Such a nucleation process is different from the nucleation of primary $\mathrm{Al}$ grains in inoculated aluminium alloys, where the total number of inoculant particles, for example $\mathrm{TiB}_{2}$, does not change with cooling rate.

In addition, cooling rate also influences the growth velocity of nucleated primary $\mathrm{Si}$ particles as well as the solute diffusion field around growing Si particles. During the growth of PSPs, a Si-depleted zone will be developing around the particles, where the driving force for nucleation of new PSPs on AlP particles will be reduced. This is, in principle, the same as the solute segregation stifling effect [17, 54-57] for nucleation of primary $\mathrm{Al}$ phase in inoculated aluminium alloys. At higher cooling rates, PSPs have less time to grow into larger size (Fig. 6) while the Sidepleted zone is smaller. Therefore, more PSPs can nucleate on AlP particles in between growing $\mathrm{Si}$ particles. Therefore, the total number density of PSPs increases with increasing cooling rate.

However, the maximum nucleation undercoooling of PSPs in the present P inoculated alloy (Fig. $9 \mathrm{~b}$ ) is much larger than that of $\mathrm{Al}$ grains in the $\mathrm{Al}-\mathrm{Cu}$ alloys [17]. Such a nucleation behaviour may be due to the in situ nucleation and growth of AlP particles during cooling and solidification (according to the phase diagram), while $\mathrm{TiB}_{2}$ particles are very stable. By forming new potent AlP particles in the melt during solidification, nucleation of primary Si particles is still possible.

A surprising finding in this work is the decrease in minimum nucleation undercooling of PSPs with increasing cooling rate in the $\mathrm{P}$ inoculated alloy (Figs. 7a, 9a). According to the athermal nucleation theory and free growth criteria proposed for nucleation of aluminium grains on potent flat inoculant particles $[58,59]$ and heterogeneous nucleation model for nucleation of magnesium grains on potent spherical substrates [60], the minimum nucleation undercooling is determined by the size of the largest potent inoculant particles available while the nucleation undercooling decreases with increasing size of potent nucleation site. Thus, a slow cooling rate will favour an earlier nucleation of PSPs, namely a smaller nucleation undercooling of PSPs due to larger size of potent AlP particles. Such a contradiction maybe attributed to the faceted growth mechanism of PSPs, which is largely different from the fast continuous 
growth kinetics of non-faceted primary $\mathrm{Al}$ grains. At small undercoolings, the growth of $\mathrm{Si}$ particles on AlP substrates is based on two-dimensional nucleation, which is very slow [47]. When the alloy melt is cooled down to the liquidus temperature of the experimental $\mathrm{Al}-\mathrm{Si}-\mathrm{Cu}$ alloy with a smaller cooling rate, AlP particles will reach a larger size due to longer time of growth and coarsening. Provided that free growth radius also exists for nucleation of PSPs, it will take a longer time for $\mathrm{Si}$ atoms to cover the surface of large AlP particles and grow into a free growth radius of PSP (equal to the substrate size). It has to be noted that the nucleation of PSPs in $\mathrm{P}$ inoculated Al-Si alloys is more complex than the nucleation of primary $\mathrm{Al}$ grains in inoculated aluminium alloys. In the former case, two processes are included: in situ precipitation and growth of AlP particles and nucleation of PSPs on AlP. Since both AlP and Si particle are faceted crystals, kinetic undercooling cannot be neglected when considering the nucleation of PSPs. To verify if free growth model is valid for the nucleation of PSPs on AlP substrates, development of reliable physical model and corresponding numerical simulation models is yet needed, though challenging.

In the present work, the nucleation kinetics of PSPs under the influence of $\mathrm{P}$ inoculation at different cooling rates has been quantitatively studied. It has been observed that $\mathrm{P}$ addition and higher cooling rates enhance nucleation of high number density of PSPs, refine the size of PSPs. At the same time, the morphologies of PSPs have also been changed. The influence of $\mathrm{P}$ addition on the growth mechanism and growth velocity of PSPs has been reported in another work [46].

\section{Conclusions}

A novel quantitative study of heterogeneous nucleation behaviour of primary silicon particles (PSPs) during solidification of hypereutectic $\mathrm{Al}-\mathrm{Si}(-\mathrm{Cu})$ alloys under the influence of $\mathrm{P}$ inoculation has been carried out through a combination of the in situ micro-focus X-radiography and TP-1 type solidification study. The major results are summarized as follows.

Both TP-1 type solidification test and in situ X-radiography confirmed that $\mathrm{P}$ addition has the influence of promoting the nucleation of and therefore refining the primary Si particles in hypereutectic $\mathrm{Al}-$ $\mathrm{Si}$ alloys. This has been attributed to the formation of AlP particles in the melt, which can act as potent nucleation substrates.

The $\mathrm{P}$ inoculation greatly extends the nucleation temperature range of primary $\mathrm{Si}$ particles by reducing the minimum nucleation undercooling and increasing the maximum nucleation undercooling. Nucleation of the majority of the particles happens within the temperature range of $10 \mathrm{~K}$ after the nucleation starts.

The nucleation rate curves of primary Si particles, as a function of undercooling, in both inoculated and non-inoculated alloys show a log-normal shape. In the $\mathrm{P}$ inoculated alloy, the peak nucleation rate is much higher than the non-inoculated alloy.

Cooling rate has a strong effect on the nucleation kinetics of PSPs. The number density of PSPs increases with increasing cooling rate, which is more significant for the P inoculated alloy. The maximum nucleation undercooling increases with increasing cooling rate. For the $\mathrm{P}$ inoculated alloy, the minimum nucleation undercooling decreases with increasing cooling rate. This is different from the non-inoculated alloy and primary $\mathrm{Al}$ grain nucleation in inoculated Al alloys, for which the minimum nucleation undercooling increases or almost does not change with cooling rate. This has been attributed to the slow faceted growth mechanism of PSPs on AlP substrate. Higher cooling rate also enhances the peak nucleation rate in the $\mathrm{P}$ inoculated alloy.

\section{Acknowledgements}

The financial support by The Research Council of Norway (PRIMARL Project, Project Number: 236675) and industrial partners Hydro Aluminium AS and Alcoa Norway ANS is greatly acknowledged.

\section{Funding}

Open Access funding provided by NTNU Norwegian University of Science and Technology (incl St. Olavs Hospital - Trondheim University Hospital)

\section{Compliance with ethical standards}

Conflict of interest The authors declare that they have no conflict of interest. 
Electronic supplementary material: The online version of this article (https://doi.org/10.1007/s108 53-020-05095-3) contains supplementary material, which is available to authorized users.

Open Access This article is licensed under a Creative Commons Attribution 4.0 International License, which permits use, sharing, adaptation, distribution and reproduction in any medium or format, as long as you give appropriate credit to the original author(s) and the source, provide a link to the Creative Commons licence, and indicate if changes were made. The images or other third party material in this article are included in the article's Creative Commons licence, unless indicated otherwise in a credit line to the material. If material is not included in the article's Creative Commons licence and your intended use is not permitted by statutory regulation or exceeds the permitted use, you will need to obtain permission directly from the copyright holder. To view a copy of this licence, visit http://creativecommons.org/licen ses/by $/ 4.0 /$.

\section{References}

[1] Vijeesh V, Prabhu KN (2014) Review of microstructure evolution in hypereutectic Al-Si alloys and its effect on wear properties. Trans Indian Inst Met 67(1):1-18

[2] Javidani M, Larouche D (2014) Application of cast A1-Si alloys in internal combustion engine components. Int Mater Rev 59(3):132-158

[3] Tenekedjiev N, Gruzleski JE (1990) Hypereutectic aluminium-silicon casting alloys - a review. Cast Metals 3(2):96-105

[4] Chen Y, Hu Z, Xu Y, Wang J, Schützendübe P, Huang Y, Liu Y, Wang Z (2019) Microstructure evolution and interface structure of Al-40 wt $\%$ Si composites produced by highenergy ball milling. J Mater Sci Technol 35(4):512-519

[5] Fredriksson H, Hillert M, Lange N (1973) The modification of aluminum-silicon alloys by sodium. $\mathrm{J}$ Inst Met 101:285-299

[6] Xu CL, Wang HY, Liu C, Jiang QC (2006) Growth of octahedral primary silicon in cast hypereutectic Al-Si alloys. J Cryst Growth 291(2):540-547

[7] Xu CL, Jiang QC (2006) Morphologies of primary silicon in hypereutectic Al-Si alloys with melt overheating temperature and cooling rate. Mater Sci Eng, A 437(2):451-455
[8] Atasoy OA, Yilmaz F, Elliott R (1984) Growth structures in aluminium-silicon alloys I. The coupled zone. J Cryst Growth 66(1):137-146

[9] Liang D, Bayraktar Y, Jones H (1995) Formation and segregation of primary silicon in Bridgman solidified Al18.3 wt\% Si alloy. Acta Metall Mater 43(2):579-585

[10] Kasprzak W, Sahoo M, Sokolowski J, Yamagata H, Kurita H (2009) The effect of the melt temperature and the cooling rate on the microstructure of the $\mathrm{Al}-20 \% \mathrm{Si}$ alloy used for monolithic engine blocks. Int J Metalcast 3(3):55-71

[11] Ullah MW, Carlberg T (2011) Silicon crystal morphologies during solidification refining from $\mathrm{Al}-\mathrm{Si}$ melts. J Cryst Growth 318(1):212-218

[12] Wang W, Bian X, Qin J, Syliusarenko SI (2000) The atomicstructure changes in Al-16 pct Si alloy above the liquidus. Metall Mater Trans A 31(9):2163-2168

[13] Eskin GI, Eskin DG (2004) Some control mechanisms of spatial solidification in light alloys. Z Metall 95(8):682-690

[14] Kasprzak W, Sediako D, Walker M, Sahoo M, Swainson I (2011) Solidification analysis of an Al-19 Pct Si alloy using in situ neutron diffraction. Metall Mater Trans A 42(7):1854-1862

[15] Sterner-Rainer R (1933) Aluminium silicon alloy with a phosphorus content of 0.001 to $0.1 \%$. Google Patents

[16] Ho CR, Cantor B (1995) Heterogeneous nucleation of solidification of $\mathrm{Si}$ in $\mathrm{Al}-\mathrm{Si}$ and $\mathrm{Al}-\mathrm{Si}-\mathrm{P}$ alloys. Acta Metall Mater 43(8):3231-3246

[17] Xu Y, Casari D, Du Q, Mathiesen RH, Arnberg L, Li Y (2017) Heterogeneous nucleation and grain growth of inoculated aluminium alloys: an integrated study by in situ $\mathrm{X}$-radiography and numerical modelling. Acta Mater 140:224-239

[18] Xu Y, Casari D, Mathiesen RH, Li Y (2018) Revealing the heterogeneous nucleation behavior of equiaxed grains of inoculated $\mathrm{Al}$ alloys during directional solidification. Acta Mater 149:312-325

[19] Xu Y, Casari D, Mathiesen RH, Li Y (2019) Revealing the heterogeneous nucleation and growth behaviour of grains in inoculated aluminium alloys during solidification. Springer International Publishing, Cham, pp 1665-1675

[20] Fan Z, Wang Y, Zhang Y, Qin T, Zhou XR, Thompson GE, Pennycook T, Hashimoto T (2015) Grain refining mechanism in the Al/Al-Ti-B system. Acta Mater 84:292-304

[21] Easton MA, Qian M, Prasad A, StJohn DH (2016) Recent advances in grain refinement of light metals and alloys. Curr Opin Solid State Mater Sci 20(1):13-24

[22] Greer AL (2016) Overview: application of heterogeneous nucleation in grain-refining of metals. J Chem Phys 145(21):211704 
[23] Murphy AG, Mathiesen RH, Houltz Y, Li J, Lockowandt C, Henriksson K, Zimmermann G, Melville N, Browne DJ (2016) XRMON-SOL: isothermal equiaxed solidification of a grain refined $\mathrm{Al}-20 \mathrm{wt} \% \mathrm{Cu}$ alloy. J Cryst Growth 440:38-46

[24] Liotti E, Arteta C, Zisserman A, Lui A, Lempitsky V, Grant PS (2018) Crystal nucleation in metallic alloys using x-ray radiography and machine learning. Sci Adv 4(4):eaar4004

[25] Olmedilla A, Založnik M, Combeau H (2019) Quantitative 3D mesoscopic modeling of grain interactions during equiaxed dendritic solidification in a thin sample. Acta Mater 173:249-261

[26] Wang Y, Fang CM, Zhou L, Hashimoto T, Zhou X, Ramasse QM, Fan Z (2019) Mechanism for Zr poisoning of Al-Ti-B based grain refiners. Acta Mater 164:428-439

[27] Kyffin WJ, Rainforth WM, Jones H (2001) Effect of treatment variables on size refinement by phosphide inoculants of primary silicon in hypereutectic Al-Si alloys. Mater Sci Technol 17(8):901-905

[28] Yu W, Zhang Y, Jiang A, Yan T, Du H, Tian Y, Lin X, Zheng $\mathrm{H}$, Tian X (2017) Multi-step nucleation in Al-Si liquids catalyzed by a Ni-Si master alloy. Mater Des 132:385-391

[29] Kyffin WJ, Rainforth WM, Jones H (2001) Effect of phosphorus additions on the spacing between primary silicon particles in a Bridgman solidified hypereutectic Al-Si alloy. J Mater Sci 36(11):2667-2672. https://doi.org/10.1023/A: 1017904627733

[30] Zhang Z-H, Bian X-F, Wang Y, Liu X (2001) Refinement and thermal analysis of hypereutectic Al-25\% Si alloy. Trans Nonferrous Met Soc China 11(3):374-377

[31] Wang R-Y, Lu W-H, Hogan LM (1995) Twin related silicon crystals in Al-Si alloys and their growth mechanism. Mater Sci Technol 11(5):441-449

[32] Mathiesen RH, Arnberg L, Li Y, Meier V, Schaffer PL, Snigireva I, Snigirev A, Dahle AK (2011) X-ray videomicroscopy studies of eutectic Al-Si solidification in $\mathrm{Al}-\mathrm{Si}-$ Cu. Metall Mater Trans A 42(1):170-180

[33] Shahani AJ, Gulsoy EB, Poulsen SO, Xiao X, Voorhees PW (2016) Twin-mediated crystal growth: an enigma resolved. Sci Rep 6:28651

[34] Shahani AJ, Xiao X, Skinner K, Peters M, Voorhees PW (2016) Ostwald ripening of faceted Si particles in an Al-SiCu melt. Mater Sci Eng, A 673:307-320

[35] Mirihanage WU, Browne DJ (2011) As-cast grain size distribution prediction for grain refined castings via simulating free equiaxed dendrite transport during solidification. Int Found Res 63(1):28-33

[36] Hall RN, Racette JH (1964) Diffusion and solubility of copper in extrinsic and intrinsic germanium, silicon, and gallium Arsenide. J Appl Phys 35(2):379-397
[37] Dorward R, Kirkaldy J (1968) Thermodynamic properties of copper and gold in silicon and germanium. Trans Met Soc AIME 242(10):2055-2061

[38] Darlapudi A, Felberbaum M, Mathiesen RH, Dahle AK (2016) The influence of $\mathrm{Cu}$ on eutectic nucleation and morphology in hypoeutectic Al-Si alloys. Springer International Publishing, Cham, pp 1475-1482

[39] Zuo M, Liu XF (2011) Series of Al-P master alloy and excellent refining performance on hypereutectic A390 alloys. In: Advanced materials research. Trans Tech Publ, pp 613-616

[40] Qiao H, Zhu X, Gao T, Wu Y, Liu X (2015) Influence of deformation on the microstructure and low-temperature refining behavior of Al-35P master alloy. J Mater Sci Technol 31(4):391-396

[41] Murphy AG, Mirihanage WU, Browne DJ, Mathiesen RH (2015) Equiaxed dendritic solidification and grain refiner potency characterised through in situ X-radiography. Acta Mater 95:83-89

[42] Murphy AG, Browne DJ, Mirihanage WU, Mathiesen RH (2013) Combined in situ X-ray radiographic observations and post-solidification metallographic characterisation of eutectic transformations in $\mathrm{Al}-\mathrm{Cu}$ alloy systems. Acta Mater 61(12):4559-4571

[43] Bjurenstedt A, Casari D, Seifeddine S, Mathiesen RH, Dahle AK (2017) In-situ study of morphology and growth of primary $\alpha-\mathrm{Al}(\mathrm{FeMnCr}) \mathrm{Si}$ intermetallics in an $\mathrm{Al}-\mathrm{Si}$ alloy. Acta Mater 130:1-9

[44] Casari D, Mirihanage WU, Falch KV, Ringdalen IG, Friis J, Schmid-Fetzer R, Zhao D, Li Y, Sillekens WH, Mathiesen $\mathrm{RH}$ (2016) $\alpha-\mathrm{Mg}$ primary phase formation and dendritic morphology transition in solidification of a $\mathrm{Mg}-\mathrm{Nd}-\mathrm{Gd}-\mathrm{Zn}-$ Zr casting alloy. Acta Mater 116:177-187

[45] Xu Y, Deng Y, Casari D, Mathiesen RH, Li Y (2020) In-situ $\mathrm{X}$-radiographic study of nucleation and growth behaviour of primary silicon particles during solidification of a hypereutectic Al-Si alloy. J Alloy Compd 832:154948

[46] Xu Y, Deng Y, Casari D, Mathiesen RH, Liu X, Li Y (2020) Growth kinetics of primary Si particles in hypereutectic Al$\mathrm{Si}$ alloys under the influence of $\mathrm{P}$ inoculation: experiments and modelling. J Alloys Compd. https://doi.org/10.1016/j.ja llcom.2020.155323

[47] Kurz W, Fisher DJ (1998) Fundamentals of solidification, 4th edn. Trans Tech Publication LTD, Stafa-Zurich

[48] Men H, Jiang B, Fan Z (2010) Mechanisms of grain refinement by intensive shearing of AZ91 alloy melt. Acta Mater 58(19):6526-6534

[49] Yu W, Zhang Y, Jiang A, Yan T, Tian Y, Zheng H, Lin X, Tian X (2017) Promoted nucleation of potent substrates 
assisted with $\mathrm{Al}-10 \mathrm{Si}-2 \mathrm{Fe}$ master alloy in $\mathrm{Al}-\mathrm{Si}$ alloys. Mater Lett 207:93-95

[50] Liang S-M, Schmid-Fetzer R (2013) Thermodynamic assessment of the Al-P system based on original experimental data. Calphad 42:76-85

[51] Liang S-M, Schmid-Fetzer R (2014) Phosphorus in Al-Si cast alloys: thermodynamic prediction of the AlP and eutectic ( $\mathrm{Si}$ ) solidification sequence validated by microstructure and nucleation undercooling data. Acta Mater 72:41-56

[52] Nogita K, McDonald SD, Tsujimoto K, Yasuda K, Dahle AK (2004) Aluminium phosphide as a eutectic grain nucleus in hypoeutectic Al-Si alloys. Microscopy 53(4):361-369

[53] Dahle AK, Nogita K, McDonald SD, Dinnis C, Lu L (2005) Eutectic modification and microstructure development in Al-Si Alloys. Mater Sci Eng, A 413-414:243-248

[54] Quested TE, Greer AL (2005) Grain refinement of Al alloys: mechanisms determining as-cast grain size in directional solidification. Acta Mater 53(17):4643-4653

[55] Shu D, Sun B, Mi J, Grant PS (2011) A quantitative study of solute diffusion field effects on heterogeneous nucleation and the grain size of alloys. Acta Mater 59(5):2135-2144
[56] StJohn DH, Qian M, Easton MA, Cao P (2011) The interdependence theory: the relationship between grain formation and nucleant selection. Acta Mater 59(12):4907-4921

[57] Du Q, Li YJ (2014) An extension of the Kampmann-Wagner numerical model towards as-cast grain size prediction of multicomponent aluminum alloys. Acta Mater 71:380-389

[58] Quested TE, Greer AL (2005) Athermal heterogeneous nucleation of solidification. Acta Mater 53(9):2683-2692

[59] Greer AL, Bunn AM, Tronche A, Evans PV, Bristow DJ (2000) Modelling of inoculation of metallic melts: application to grain refinement of aluminium by Al-Ti-B. Acta Mater 48(11):2823-2835

[60] Qian M (2007) Heterogeneous nucleation on potent spherical substrates during solidification. Acta Mater 55(3):943-953

Publisher's Note Springer Nature remains neutral with regard to jurisdictional claims in published maps and institutional affiliations. 